ISSN: 2716-1277 e-ISSN: 2716-1269

Available online at TLIC https://jlic.iain-jember.ac.id/
Journal of Language Intelligence and Culture

Fakultas Tarbiyah dan Ilmu Keguruan

IAIN Jember

Vol. 2, No.2, Page 193-214, June 2020

\title{
Tadrīs Mahārah al-Kalām ma'a al-Nāṭiq al-Aṣlī (Mazāyāhu wa Naqāiṣuhu)
}

Isra Hayati Darman, STAIN Mandailing Natal israhayatid@gmail.com

\section{Rani Ismil Hakim ${ }^{1}$}

STAIN Mandailing Natal

Ismil.he@gmail.com ${ }^{1}$

\section{ARTICLE INFO}

\section{Article History:}

Accepted: November, $19^{\text {th }} 2020$. Approved: December, 22th 2020. Published: December 2020

$$
\text { الكلمات المفتاحية: }
$$

DOI: $10.35719 / j l i c . v 2 i 2.40$

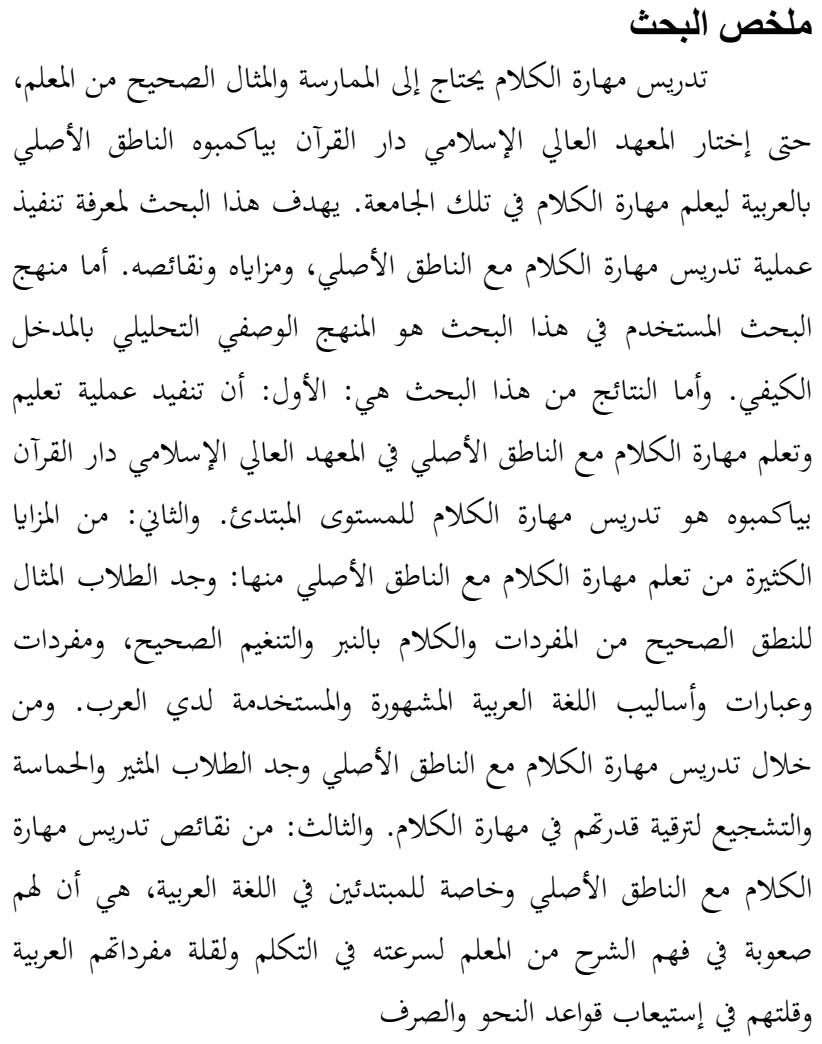




\section{ILIC \\ Journal of Language Intelegence and Culture} Keywords: speaking skill,
native speaker, advantages, disadvantages.

\begin{abstract}
Learning the speaking skill needs practice and a correct example from the teacher. Then, the Islamic Higher Institute Dar al-Qur'an Payakumbuh using the native speaker to teach the speaking skill at that institute. This research aims to find out the implementation of the process of learning the speaking skill with a native speaker, its advantages and disadvantages. The research method used in this research is the descriptive method with qualitative approach analysis. The results of this research are: The first: The process of teaching and learning the speaking skill with the native speaker at the Islamic Higher Institute Dar AlQur'an Payakumbuh is implemented to the beginner level. The second: The advantages of learning the speaking skill with the native speaker, including: The students found the example of correct pronunciation from vocabulary and speaking with correct accent, intonation, vocabulary, phrases and styles of the famous Arabic language and used by Arabs. Also, by learning the speaking skill with native speaker, the students found exciting, enthusiastic, and encouraged to upgrade their ability to speak, and the third: disadvantages of learning the speaking skill with the native speaker, which is especially for beginners in the Arabic language, they are difficult to understand the explanation from the teacher because of his speed in speaking, and lack of their Arabic vocabularies, and lack of their comprehension in grammar and morphology.
\end{abstract}

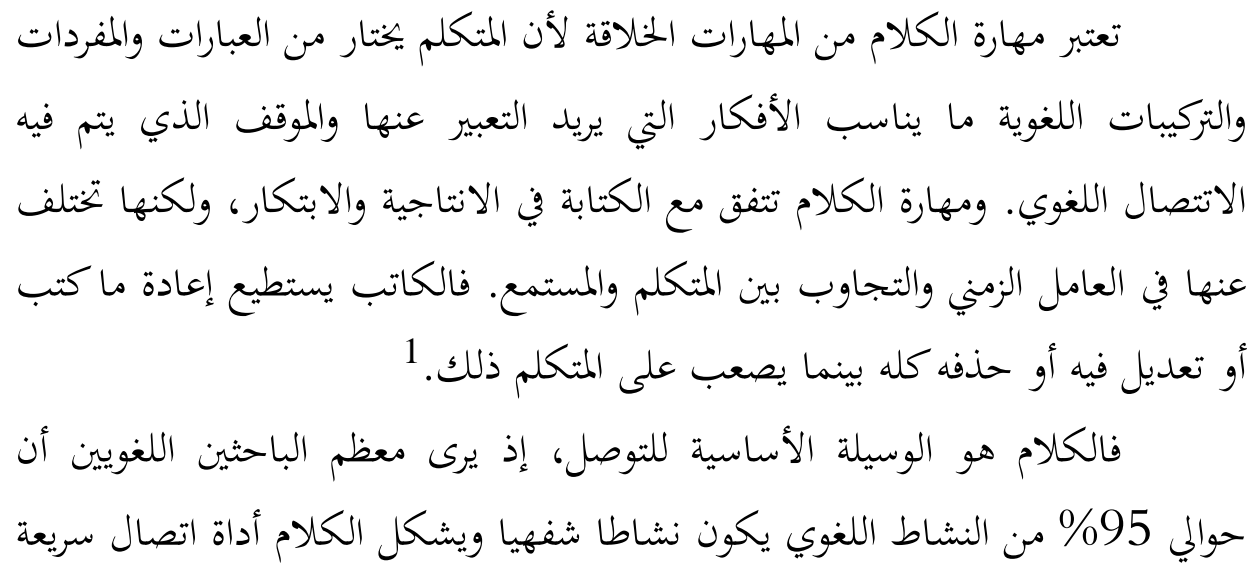

1 صلاح عبد المجيد العربي، تعلّم اللغات الحيّة وتعليمها بين النظيّة والنطبيق (بيروت: مكتبة لبنان، 


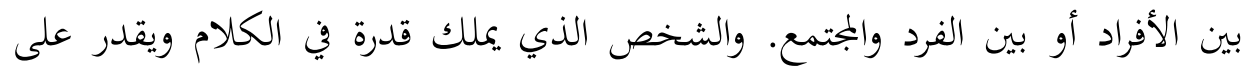

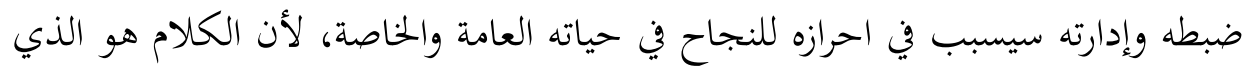

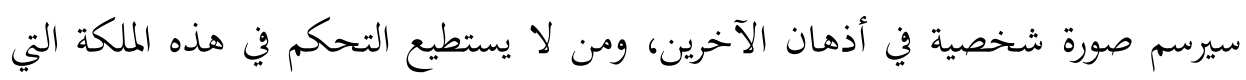

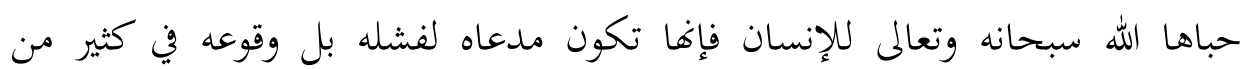

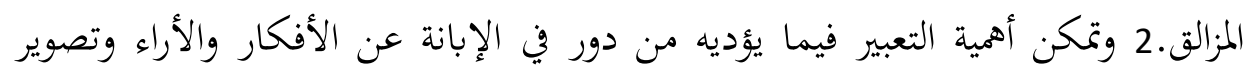
الإحساسات والمثاعر.

المعهد العالي الإسلامي دار القرآن بياكمبوه هو إحدى الجامعات الإسلامية غير

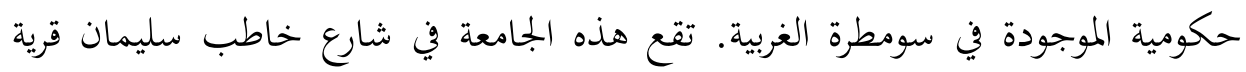

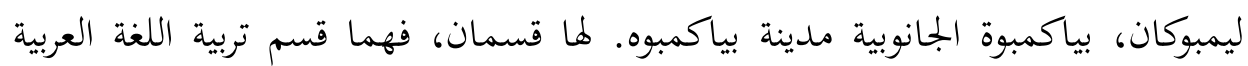

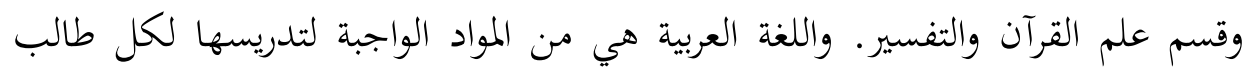
وطالبة في هذين قسمين. تدرس اللغة العربية بكثير من فروعها في قسم تربية اللغة العربية،

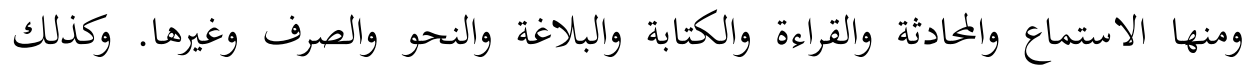

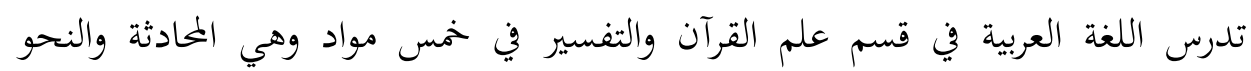
والصرف وقراءة الكتب وبلاغة القرآن.

جرى تدريس مهارة الكلام في هذين القسمين في مادة المحادثة. وتؤدي عملية

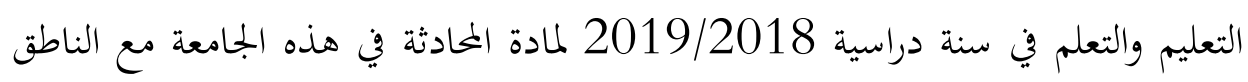

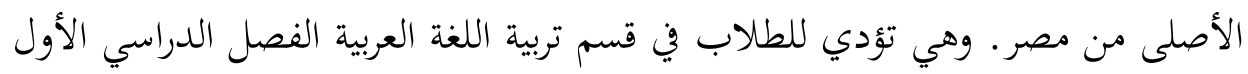

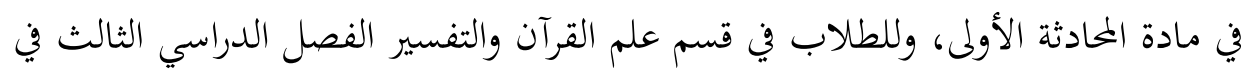
مادة اللغة العربية الأولى (المحادثة).

2 محمد صاخ الشنطي، المهارات اللغوية (المملكة العربية السعودية:دار الأندلس للنشر والتوزيع، 


\section{JLIC}

\section{1. - 1. مفهوم الكلام وأهميته وطبيعته}

يعتبر الكلام الفن الثاني من فنون اللغة العربية بعد الاستماع، وهو ترجمة

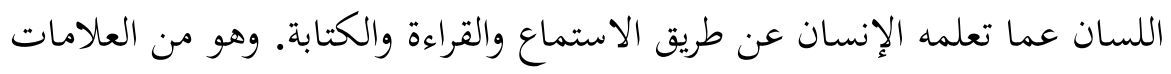

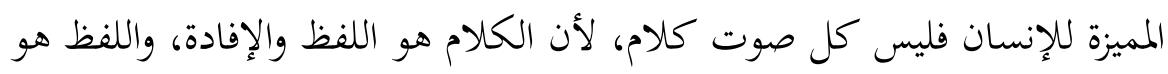

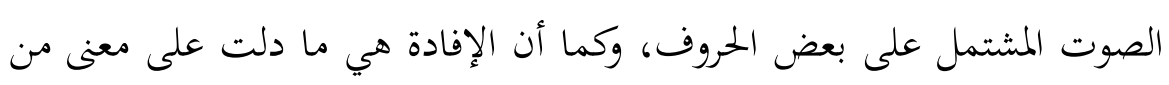
المعاني على الأقل في ذهن المتكلم. - المبن.

الكلام في أصل اللغة هو عبارة عن الأصوات المقيدة، وعند المتكلمين هو المالما

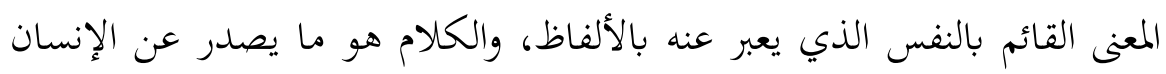

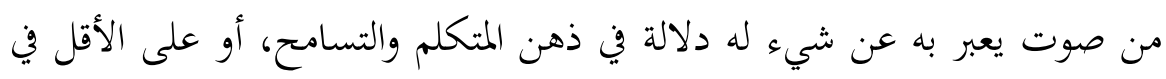

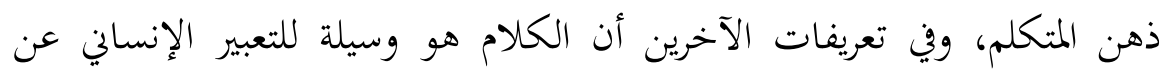
الأفكار وعن طريق جهاز النطق لتوصيلها من مرسل إلى متلقي3.

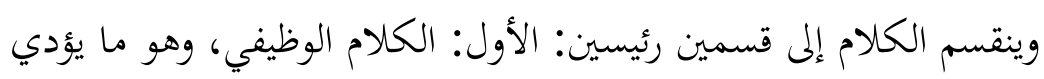

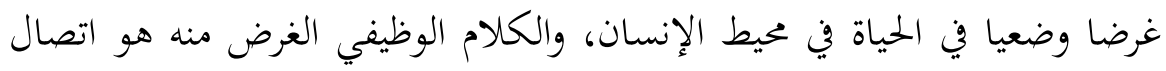

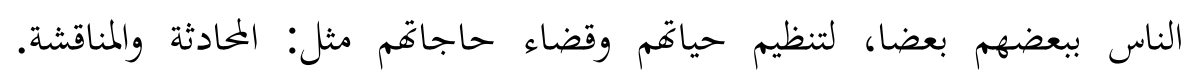
والثاني: الكلام الإبداعي، فيمكن من أن يؤثر في الحياة العامة بأفكاره وشخصيته

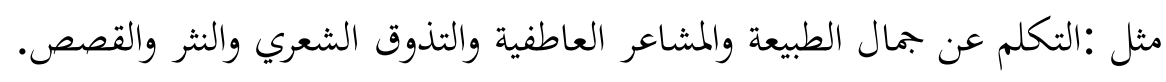

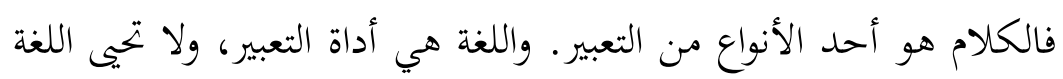

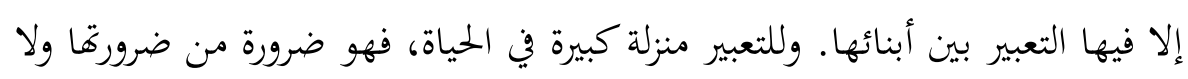

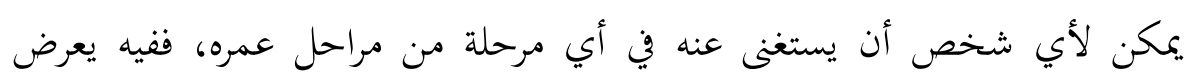
الأفراد أفكارهم ومشاعرهم باللسان أو القلم. وهو مظهر الفهم ووسيلة الإفهام ودليل برديل

3 صايش كهينة ويوسف خوجة سعيدة، الحادثة ودورها في تنمية مهارة التحدّث في مرحلة التعليم

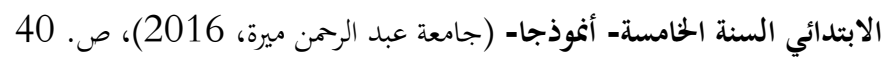


الإقناع وفيه تحقق اللغة وظيفتها. فتنمية القدرة على التعبير والحديث الصحيح أهم

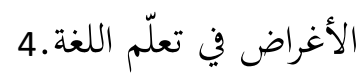

وللكلام أو التحدث أهمية كبيرة لأنه أول صور الأداء اللغوي. ولا شك أن فأن

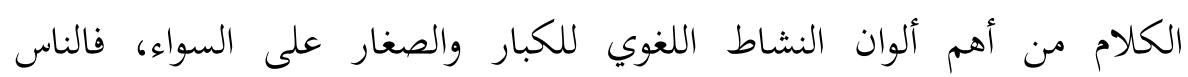
يستخدمون الكلام أكثر من الكتابة في حياقم. أي أفم يتكلمون أكثر مما يكتبون. ومن هنا يمكن اعتبار الكلام هو الشكل الرئيسي للاتصال اللغوي بالنسبة للإنسان. وعلى ذلك يعتبر الكلام أهم جزء في الممارسة اللغوية واستخداماتها وعملية الكلام يأتي استجابة طبيعية لمواقف الحياة المختلفة، وهي وسيلة

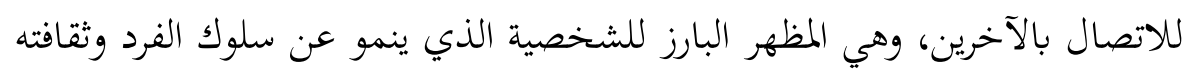

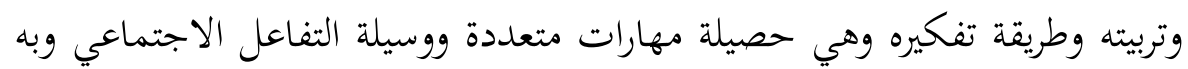
تأتحقق الأمور التالية:6 أ) الوعي بالذات، فمن خلال عملية الكلام يشعر الانسان بأن له كيانا وأنه قادر

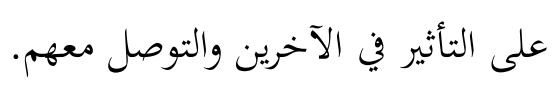
ب) التدفّ في عملية الكلام عامل من عوامل الارتياح النفسي والطمأنينة والانفراج

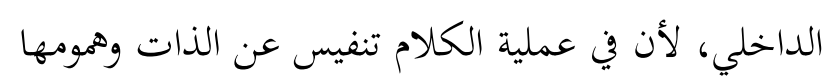
ج) عملية الكلام من أكثر النشاطات اللغوية انتشارا في الحياة العملية والعلمية والاجتماعية د) تنمية مهارة الكلام من الضرورات التي تعترضها مستلزمات التعلم لأنها وسيلة الحوار والمناقشة.

4 جاسم الجبوري وهاشم السلطاني، المناهج وطرائق تدريس اللغة العربية (عمان: مؤسسة دار الصادق

$$
\text { الثقافية. 2013)، ص. } 300
$$

5 على أحمد مدكور، تدريس فنون اللغة العربية (القاهرة: دار الفكر العربي، 2002)، ص.87

$$
6 \text { محمد صالح الشنطي، المهارات اللغوية، ...، ص. } 196
$$




\section{JLIC}

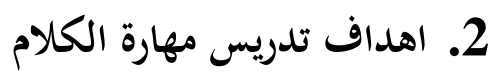

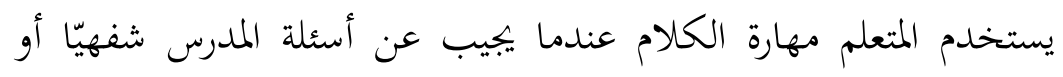

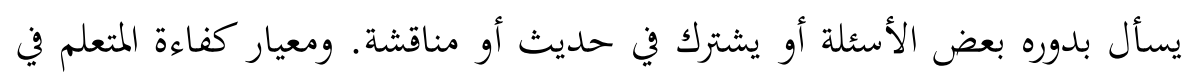
هذه المهارة هو قدرته على التعبير عن أفكاره بلغة يستطيع أهل اللغة الأصليون التبان

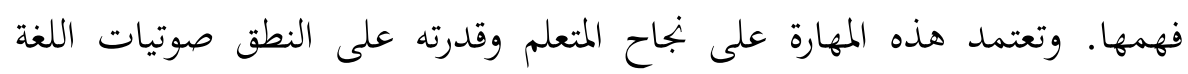

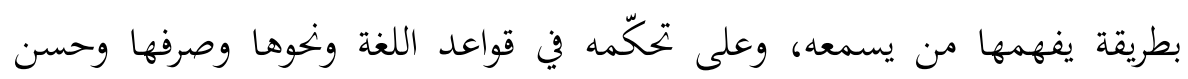

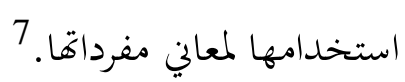
وهناك أهداف تعليم الكلام للناطقين بغير العربية ويككن عرضها فيما يلي أ) أن ينطق المتعلم أصوات اللغة العربية، وأن يؤدي أنواع النبر والتنغيم المختلفة وذلك بطريقة مقبولة من أبناء العربية. ب) أن ينطق الأصوات المتجاورة والمتشابهة. ج) أن يدرك الفرق في النطق بين الحركات القصيرة والحركات الطويلة. د) أن يعبر عن أفكاره مستخدما الصيغ النحوية المناسبة. 0) أن يعبر عن أفكاره مستخدما النظم الصحيحة لتركيب الكلمة في العربية خاصة في لغة الكلام. و) أن يستخدم بعض الخصائص اللغوية في التعبير الشفهي مثل التذكير والتأنيث

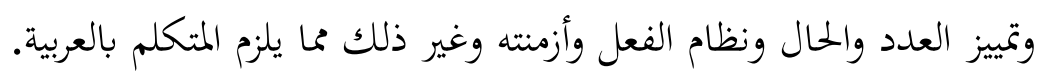

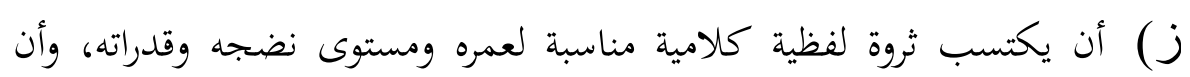
يستخدم هذه الثروة في إتمام عملية اتصال عصرية.

7 صلاح عبد المجيد العربي، تعلّم اللغات الحيّة وتعليمها بين النظريّة والتطبيق، ...، ص.138

8 محمد إيفان ألفيان، مهارة الكلام وتعليمها (البجلة العلمية "Arabia"،

107 .) (Juni 2013 
ح) أن يستخدم بعض أشكال الثقافة العربية المقبولة والمناسبة لعمره ومستواه الاجتماعي وطبيعة عمله، وأن يكتسب بعض المعلومات الأساسية عن التراث

$$
\text { العربي والإسلامي. }
$$

ط) أن يعبر عن نفسه تعبيرا واضحا ومفهوما في مواقف الحمديث البسيطة.

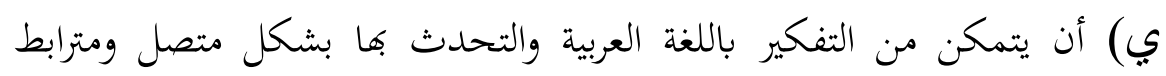

$$
\text { لفترات زمنية مقبولة. }
$$

وأما اهداف مهارة الكلام في مجال تعليم اللغة العربية كلغة أجنبية عند

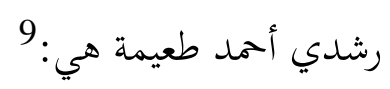

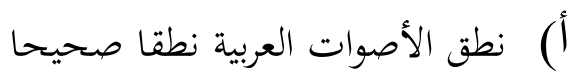

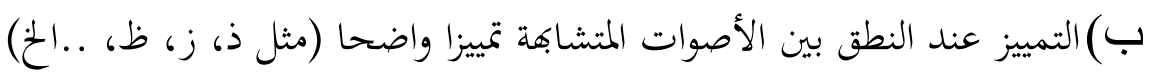
ج) التمييز عند النطق بين الحركات القصيرة والطويلة

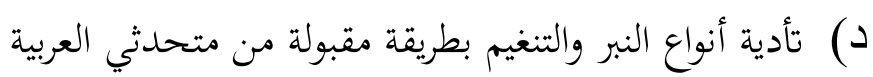

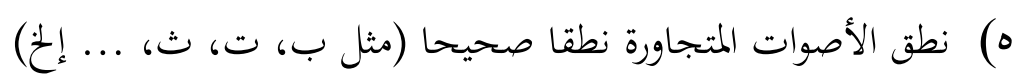

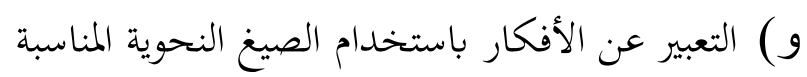

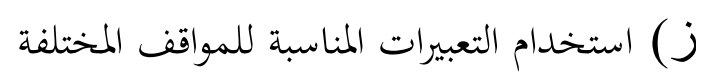
ح) استخدام عبارات المجاملة والتحية استخداما سليما في ضوء فهمه للثقافة العربية

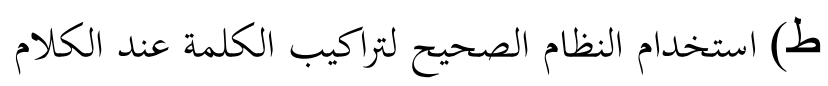

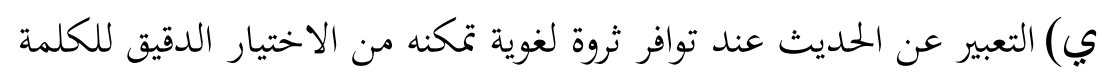

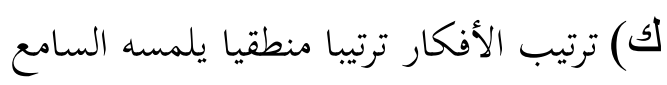

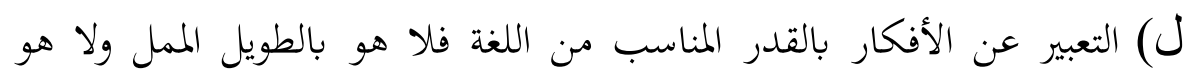
بالقصير المخل

9 فتحي علي يونس وممد عبد الرؤوف الشيخ، المرجع في تعليم اللغة العربية للأجانب من النظرية إلى

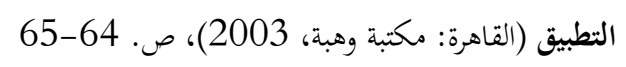




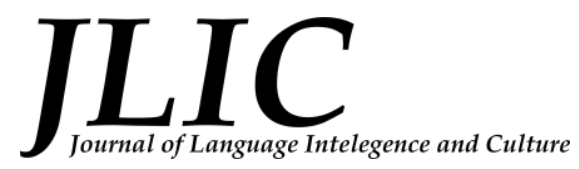

م) التحدث بشكل متصل ومترابط لفترات زمنية مقبولة مما ينبئ عن ثقته بالنفسي وقدرته على مواجهة الآخرين

ن) نطق الكلمات المنونة نطقا صحيحا يميز التنوين عن غيره من الظواهر

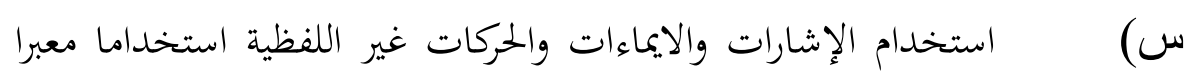
عما يريد توصيله من أفكار

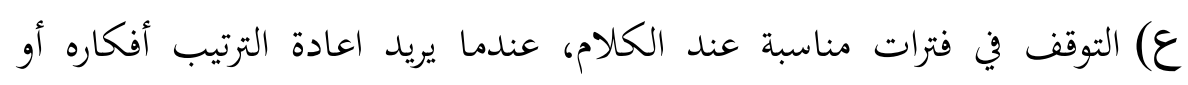
توضيح شيء منها، أو مراجعة صياغة بعض ألفاظه

ف) الاستجابة لما يدور أمامه من حديث استجابة تلقائية. ينوع فيها أشكال التعبير

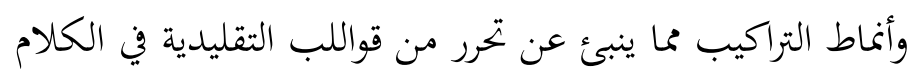

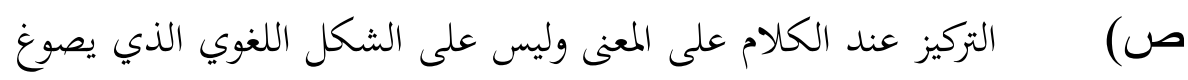
فيه هذا المعنى

ق) تغيير مجرى الحديث بكفاءة عندما يتطلب المواقف ذلك هلك ر) حكاية الخبرات الشخصية بطريقة جذابة مناسبة ش) إلقاء خطبة قصيرة مكتملة العناصر ت) إدارة مناقشة في موضوع معين، وتحديد أدوار الأعضاء المشتركين فيهاء واستخلاص النتائج من بين الآراء التي يطرحها الأعضاء ث) إدارة الحوار تليفونى مع أحد الناطقين بالعربية

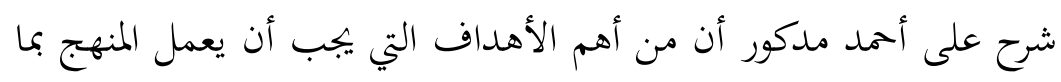

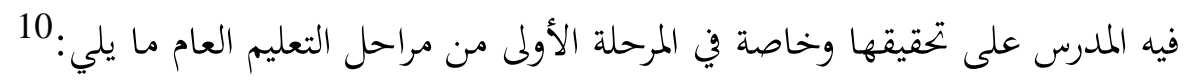
أ) تطوير وعي الطفل بالكلمات الشفوية كوحدات لغوية ب) إثراء ثروته اللفظية الشفهية ج) تقويم روابط المعنى عنده د) تمكينه من تشكيل الجمل وتركيبها

10 على أحمد مدكور، تدريس فنون اللغة العربية، ... ، ص.93 


$$
\begin{aligned}
& \text { 0) تنمية قدرته على تنظيم الأفكار في وحدات لغوية } \\
& \text { و) تحسين هجائه ونطقه } \\
& \text { ز) استخدامه للتعبير القصصى المسلّى. }
\end{aligned}
$$

وإذا ما بحاوز التلميذ هذه الحلقة (أو حتى قبيل غايتها) إلى الحلقة الثانية الثماني

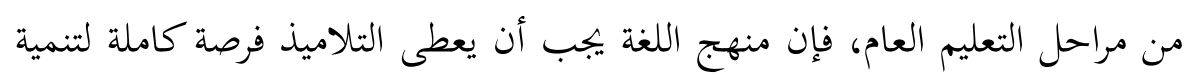

$$
\text { المهارات الآتية:11 } 11
$$

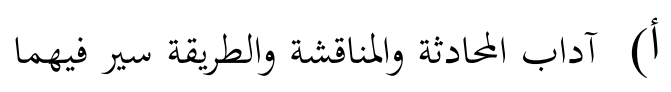$$
\text { ب) التحضير لعقد الندوة وإدارتا }
$$

ج) القدرة على أن يخطب أو يتحدث في موضوع عام أمام زملائه أو جماعة من الناس

$$
\begin{aligned}
& \text { د) القدرة على قص القصص والحكايات } \\
& \text { ه) القدرة على إعطاء التعليمات والتوجيهات التصدئ }
\end{aligned}
$$

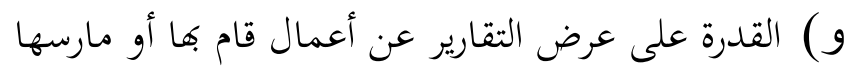

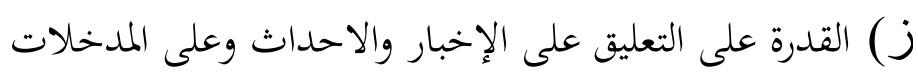

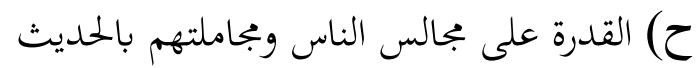

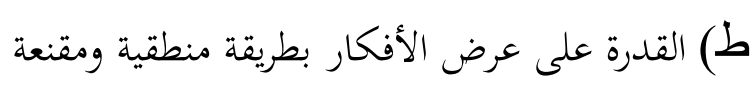

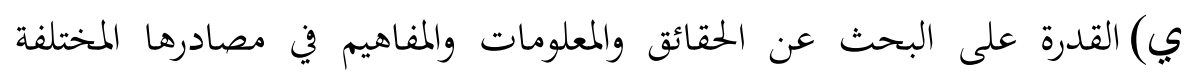

$$
\text { والمتاحة. }
$$

\section{3. مستوى تدريس مهارة الكلام}

تعتبر المحاكاة والترديد والإعادة أدنى المستويات في مزاولة مهارة الكلام

وأسهلها بينما يشكل التعبير الحرّ الخلالّق أعلى هذه المستويات وأكثرها شعوبة. 12

$$
11 \text { على أحمد مدكور، تدريس فنون اللغة العربية، ...، ص. 93-94 }
$$

12 صلاح عبد المجيد العربي، تعلّم اللغات الحيّة وتعليمها بين النظيّة والتطبيق،... ، ص.138 


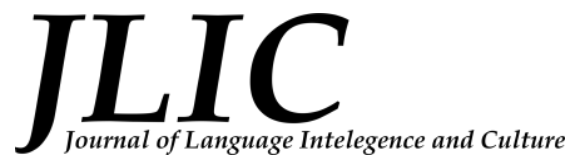

وشرح رشدي أحمد طعيمة وأصدقائه في كتاب "المرجع في مناهج التعليم اللغة العربية للناطقين بلغات أخرى"، أن هناك المستويات الثلاثة لكل مهارة في تعليم اللغة العربية للناطقين بلغات أخرى، وهي المستوى المبتدئ والمستوى المتوسط والمستوى المتقدم.

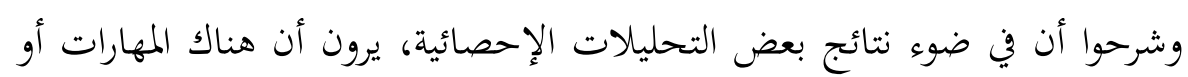
الكفايات لكل مستوى لتدريس مهارة الكلام، وهي: أ) المستوى الإبتدائي: 13 1) نطق الأصوات نطقا صحيحا.

2) التمييز عند النطق بين الأصوات المتشابهة تمييزا واضحا (مثل: ذ، ز، ظ....). 3) التمييز عند النطق بين الحركات القصيرة والطويلة. 4) تأدية أنواع النبر والتنغيم بطريقة مقبولة من متحدثي العربية.

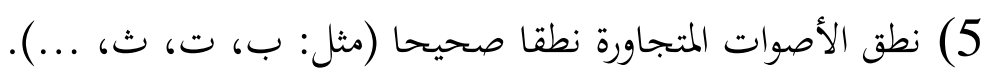
6) نطق الكلمات المنونة نطقا صحيحا يميز التنوين عن غيره من الظواهر.

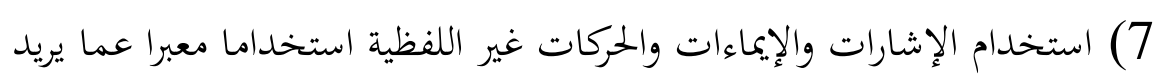

$$
\text { ب) المستوى المتوسط:14 من أفكار. }
$$

1) استخدام الصحيح لتركيب الكلمة العربية عند الكلام. 2) التمييز عند الكلام بين التعبير الجميل والعادي. 3) تقديم الناس بعضهم لبعض بطريقة مناسبة.

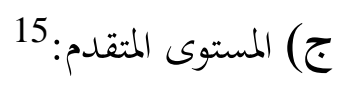

13 رشدي أحمد طعيمة وعلي أحمد مدكور وإيمان أحمد هريدي، المرجع في مناهج تعليم اللغة العربية

للناطقين بلغات أخرى (القاهرة: دار الفكري العربي، 2010)، ص. 201-202 وعلمدي

14 للناطقين بلغات أخرى، ...، ص. 204 


$$
\text { 3) (1) التعبير عن الأفكار باستخدام الصيغ النحوية المناسبة. }
$$

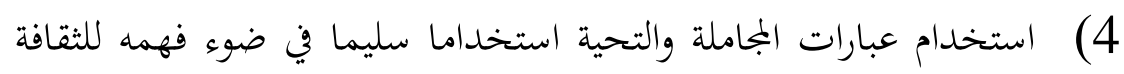

$$
\text { العربية الإسلامية. }
$$

التكيف مع مع ظروف المستمعين سواء من حيث سرعة الحديث أو من الإسمية.

$$
\text { حيث مستواه. }
$$

6) التعبير عند الحديث عن توافر ثروة لفظية تمكنه من الاختيار الدقيق للكلمة.

$$
\begin{aligned}
& \text { الانطلاق في التعبير عن الأفكار دون توقف ينبئ عن عجز. } \\
& \text { ترتيب الأفكار ترتيبا منطقيا يلمسه السامع. }
\end{aligned}
$$

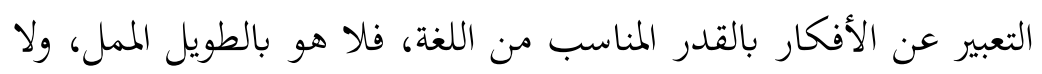

$$
\text { هو بالقصير المخل. }
$$

10) التحدث بشكل متصل ومترابط لفترات زمنية مقبولة، مما ينبئ عن ثقة

$$
\text { بالنفس وقدرة على مواجهة الآخرين. }
$$

11) التعبير عند الكلام عن استيعاب لنظام الجملة العربية، فلا يبدو في كلامه النه

$$
\text { روح الترجمة، مما ينبئ عن أنه يفكر باللغة العربية. }
$$

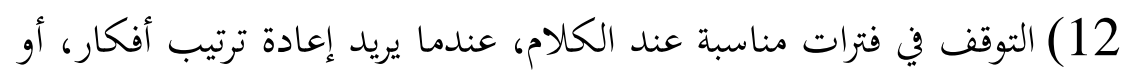

$$
\text { توضيح شيء منها، أو مراجعة صياغة بعض ألفاظه. }
$$

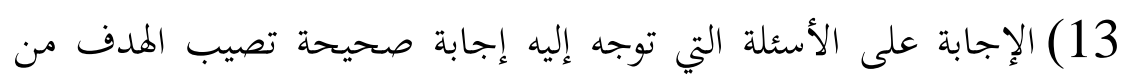

$$
\text { إلقاء السؤال. }
$$

\footnotetext{
15 رشدي أحمد طعيمة وعلي أحمد مدكور وإيمان أحمد هريدي، المرجع في مناهج تعليم اللغة العببية

$$
\text { للناطقين بلغات أخرى، ...، ص. 208-210 }
$$
}




\section{JLIC}

14) الإستجابة لما يدور أمامه من حديث استجابة تلقائية ينوع فيها أشكال

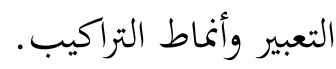

15) التركيز عند الكلام على المعنى وليس على الشكل اللغوي الذي يصوغ فيه هذا المعنى. 16) الاستغناء عن التفصيلات التي لا قيمة لها في الحديث. 17) تغيير مجرى الحديث بكفاءة عندما يتطلب الموقف ذلك. 18) معرفة الأماكن والأوقات والمواقف التي لا ينبغي الكلام فيها.

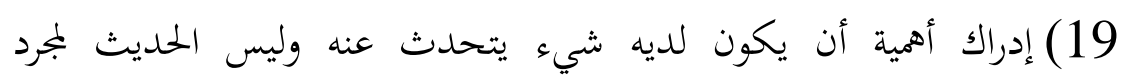

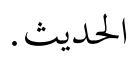

20) عدم احتكار الحديث وإدخال جميع أعضاء الجماعة في المحادثة. 21) معارضة القضية التي يذكرها المتكلم دون إحراجه. 22) حكاية الخبرات الشخصية بطريقة جذابة ومناسبة. 23) إلقاء خطبة قصيرة مكتملة العناصر.

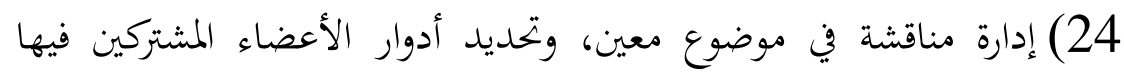
واستخلاص النتائج من بين الآراء التي يطرحها الأعضاء. 25) إدارة حوار تليفوني مع أحد الناطقين بالعربية.

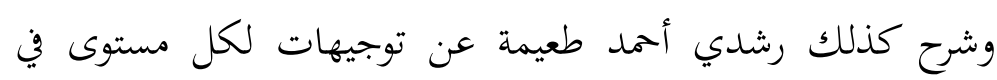
تدريس مهارة الكلام في كتابه الآخر، وهي:16

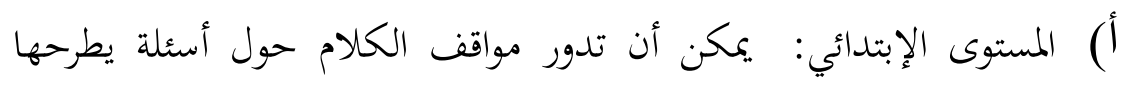

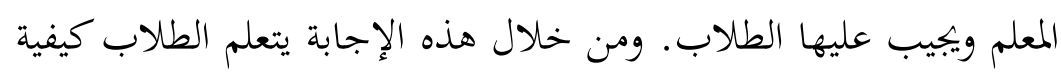

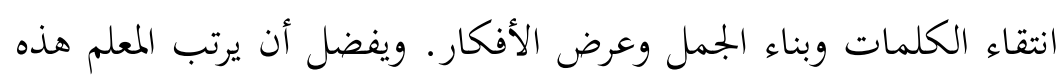

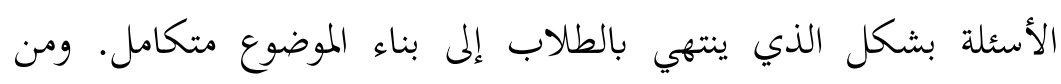

16 رشدي أحمد طعيمة، تعليم العربية لغير الناطقين بها مناهجه واساليبه (الرباط: منشورات المنظمة

$$
\text { الإسلامية للتربية والعلوم والثقافة-ايسيسكو-، 1989)، ص. } 162
$$


الموافق أيضا تكليف الطلاب بالإجابة عن التدريبات الشفهية، وحفظ بعض الحوارات والإجابة الشفوية عن الأسئلة بنص قرأوه.

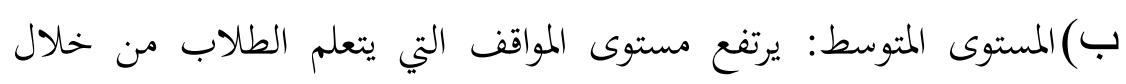

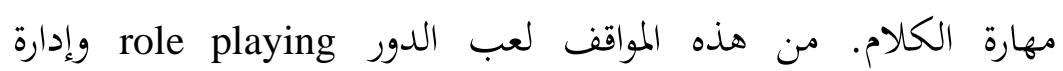

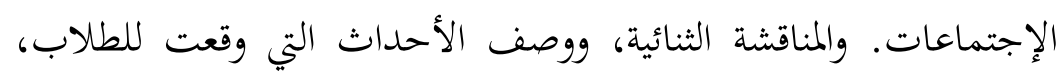

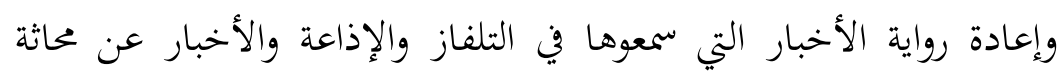
هاتفية جرت أو إلقاء تقرير مبسط وغيرها.

ج) المستوى المتقدم: هنا قد يجكي الطلاب قصة أعجبتهم أو يصفون مظهرا

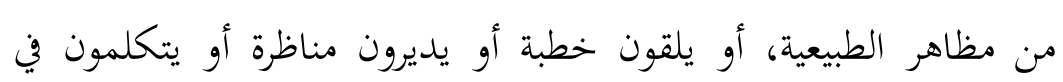

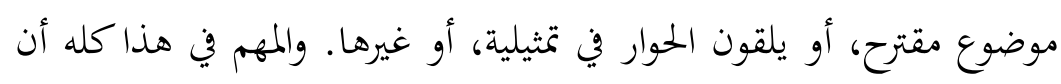

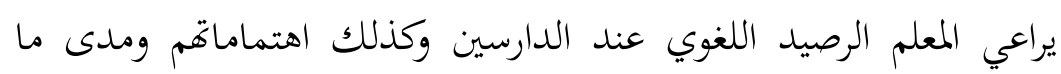
لديهم من خبرة عن موضوع الحديث.

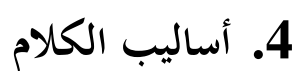

هناك أنواع أساليب الكلام أو التعبير الشفوي، وهي:17

$$
\text { أ) المحاضرة }
$$

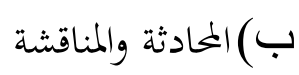

المحادثة من أهم ألوان النشاط اللغوي للصغار والكبار، حتى ينبغي أن تحظى بمكانة

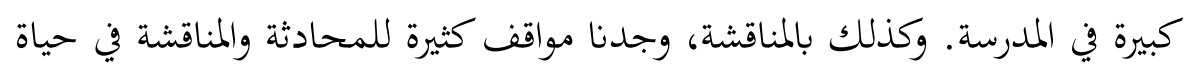

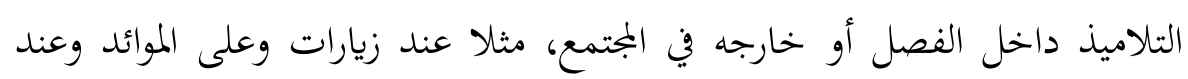

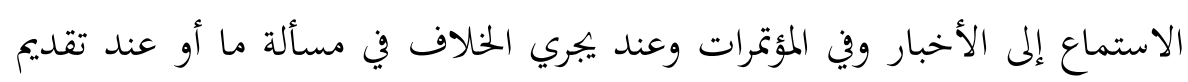
العمل وغيرها.

17 على أحمد مدكور، تدريس فنون اللغة العربية، ... ، ص. 92 


\section{JLIC}

$$
\begin{aligned}
& \text { ج) (الندوة } \\
& \text { د) المناظرة } \\
& \text { ه) الخطابة والقاء الكلمات المنات } \\
& \text { و) قص القصص والحكايات والنوادر }
\end{aligned}
$$

حكاية القصص أو النوادر من أهم ألوان التعبير الشفوي، فالأباء والأمهات يقصون القصص على أبنائهم، ويقص الأطفال قصصا على زملائهم، وكذلك بادئ بالكبار.

$$
\text { ولكي تحقق القصص أهدافها، يجب أن يراعي الأمور الآتية:18 } 18
$$

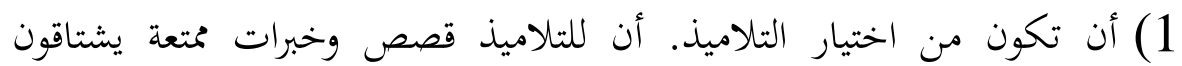
للتحدث عنها. ويمكن أن يكون اختيارها من خبرات التلاميذ المباشرة، كالنوادر

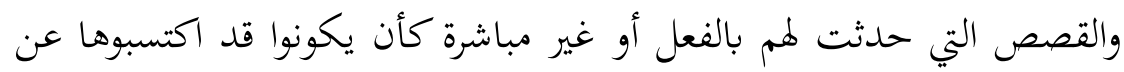
طريق القراءة أو الاستماع إلى الآخرين.

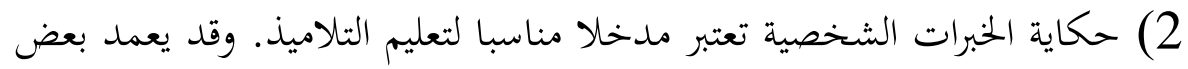
المدرسين إلى الحكايات والقصص الخيالية التي يميل إليها التلاميذ في مرحلة معينة تم يطالبوها بإعادتا.

3) تجنب الإكراه. يجب أن لا يطلب من التلاميذ حكاية قصة لايستمتعون

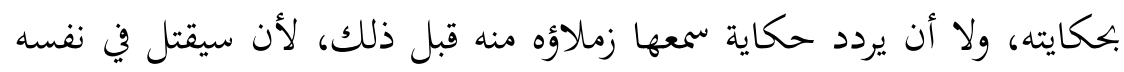
أهم عناصر القدرة على التعبير.

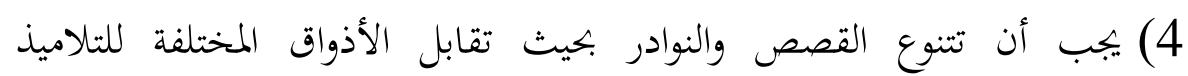
واهتمامتهم المتنوعة.

5) الاهتمام بالممارسة، يجب على المدرس الاهتمام بتوزيع الأدوار وإعطاء كل تلميذ الفرصة لقص ما يراه مناسبا من الحكايات والنوادر.

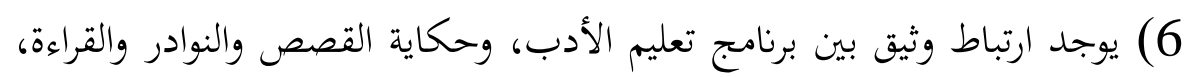

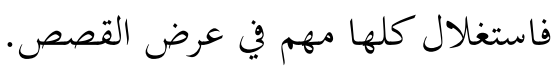

18 على أحمد مدكور، تدريس فنون اللغة العربية، ...، ص. 95-97 


$$
\text { 7) ) زينبى ألا نسمح للتلاميذ بحكاية أية قصة قبل أن يستعد لها. }
$$

\section{منهجية البحث}

هذا البحث هو البحث الكيفي بمنهج الوصفي التحليلي بالبحث الميداني. أجرت الباحثة البحث في تدريس مهارة الكلام مع الناطق الأصلي في المعهد العالي الإسلامي دار القرآن بياكمبوه من خلال طريقة المقابلة والتوثيق. أجرت الباحثة المقابلة بالطلاب في تلك الجامعة من قسم تربية اللغة العربية (في مادة المحادثة الأولى) وقسم علم القرآن والتفسير (في مادة اللغة العربية الأولى أو المحادثة) لجمع البيانات عن عملية التعليم والتعلم ومزايا ونقائص من التعليم مع الناطق الأصلي لديهم. واستخدمت الباحثة طريقة التوثيق لمعرفة المواد التعليمية المدروسة في هذا التعليم، وهي المواد التعليمية الموزعة للطلاب في كل اللقاءات الدراسية. وجرى هذا البحث من التاريج 9-14 مارس 2019.

\section{نتائج البحث ومناقشه}

\section{1. تنفيذ تدريس مهارة الكالام مع الناطق الأصلي}

هذا الشرح عن عملية تدريس مهارة الكاملام مع الناطق الأصلى في المعهد العالي الإسلامي دار القرآن بياكمبوه. جرت هذه العملية للطلاب في قسم تربية اللغة العربية الفصل الدراسي الأول في مادة المحادثة الأولى، وللطلاب في قسم علم القرآن والتفسير الفصل الدراسي الثالث في مادة اللغة العربية الأولى (المحادثة). وقد شرح رشدي أحمد طعيمة أن هناك توجيهات العامة حول تدريس مهارة الكلام التي لابد للمعلم أن يهتم بها، وهي: تدريس الكالام يعني محارسة الكلام، أن يعبر الطلاب عن خبرة، التدريب على توجيه الانتباه، عدم المقاطعم وكثرة التصحيح، والتدرج، وهو أن ينبغي لمعلم أن يهيء من مواقف الكلام ما يتناسب مع 


\section{JLIC \\ Journal of Language Intelegence and Culture}

كل مستوى من مستويات الدارسين، وهي من المستوى الإبتدائي أو المبتدئ، ثم المستوى المتوسط تم المستوى المتقدم، وقيمة الموضوع: تزداد دافعية الطلاب للتعلم

كلما كان ما يتعلمونه ذا معنى عندهم، وذا قيمة عند حياقم. 19 قد طبقت تلك التوجيهات في تدريس مهارة الكلام في المعهد العالي الإسلامي دار القرآن بياكمبوه، ومنها في تدرج مستوى الدراسي والموضوعات

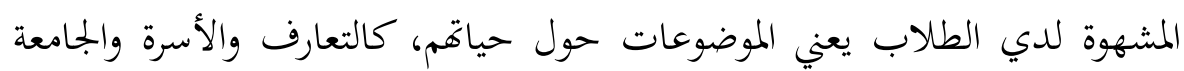
وغيرها.

وأما المحادثة هو إحدى طرق أو فنون في تدريس مهارة الكلام. جرت عملية تدريس المحادثة في الفصلين المختلفين بنفس المعلم ونفس المواد

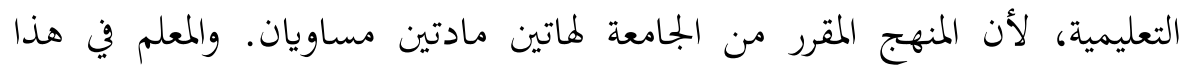
التعليم هو الناطق الأصلي من مدينة مصر.

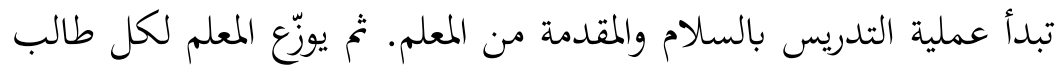
المادة التعليمة لتلك اللقاء في شكل الورقة المطبوعة بالمادة. فيها الحوار ومفردات إضافية واسئلة الإستيعاب. ثم قرأ المعلم الحوار المطبوع في الورقة بالنطق والشكل

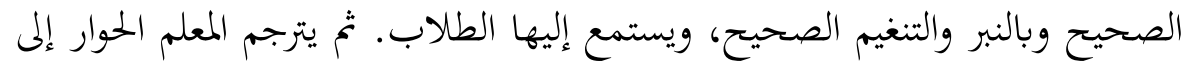

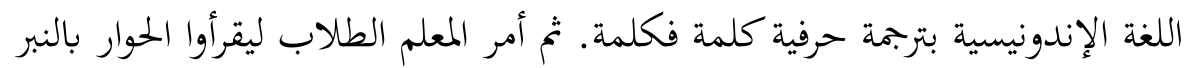
والتنغيم الصحيح كما قد قرأه المعلم جماعة، ثم يصحّح الأخطاء من قراءة الطلاب.

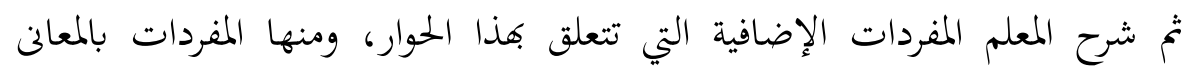

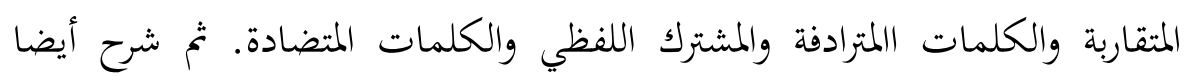

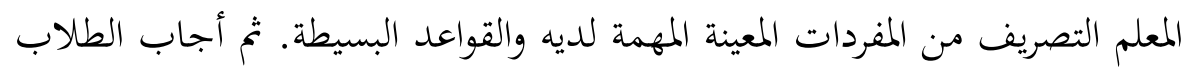

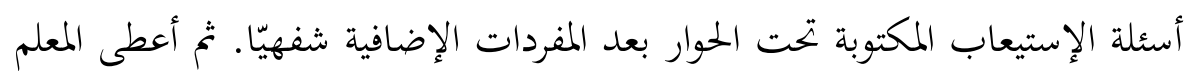

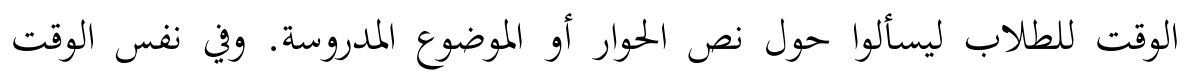

19 رشدي أحمد طعيمة، تعليم العبية لغير الناطقين بها مناهجه واساليبه، ...، ص. 160-162 
الطلاب يجفظون الحوار. والأخير، طبّق الطلاب الحوار مع المعلم مباشرة واحدا فواحدا، ثم الإختتام.

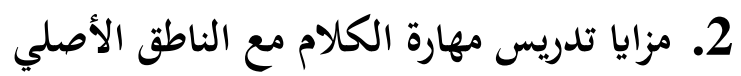

من نتائج المقابلة بالطلاب في قسم تربية اللغة العربية وقسم القرآن والتفسير لعدي

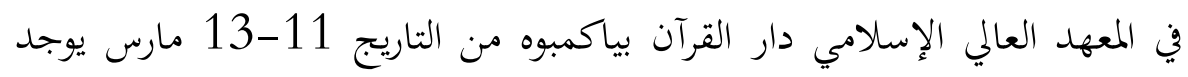
عدة المزايا في تدريس مهارة الكلام مع الناطق الأصلي في هذه الجامعة، وهي:

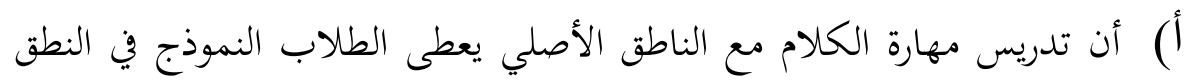

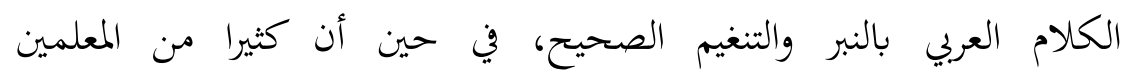

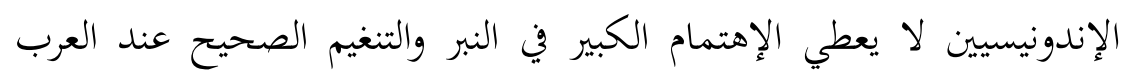

$$
\text { لأفم لا يستوعبوغما. }
$$

ب)أن عملية تدريس مهارة الكلام مع الناطق الأصلي سيعطي الطلاب أساليب

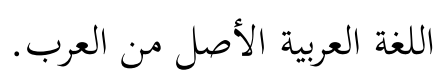

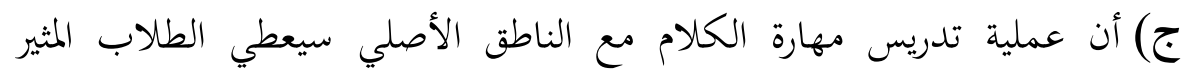

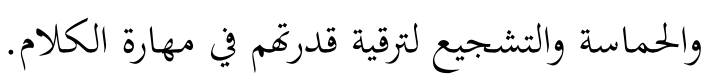

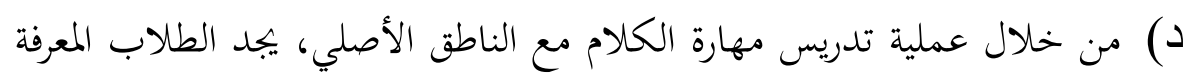

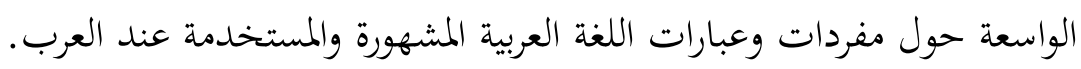

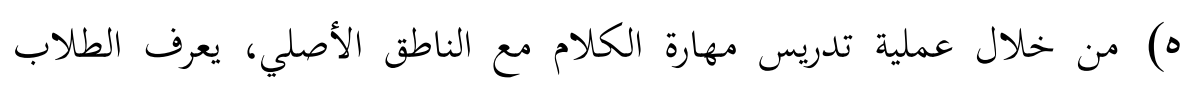

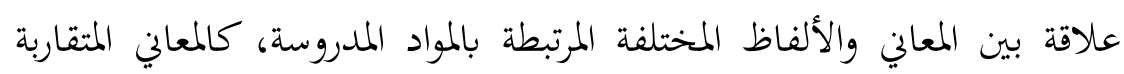
ك"اليوم الدراسي - الفصل الدراسي - العام الدراسي"، والألفاظ المترادفة ك"زميل - صديق - صاحب"، "الإختبارات - الإمتحانات"، والألفاظ المتضادة ك"أول - آخر"، "صحيح - خطأ"، "طويل - قصير"، وغيرها. 


\section{JLIC}

3. نقائص تدريس مهارة الكلام مع الناطق الأصلي

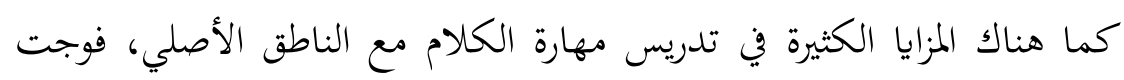

عدة النقائص أو المشكلات في هذه عملية التعليم والتعلم، ومنها:

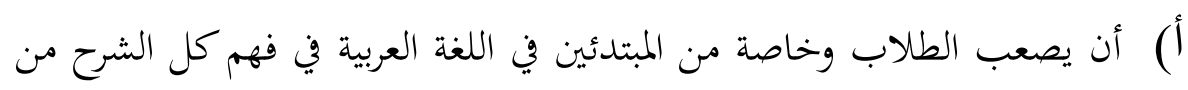

المعلم لأن قلة مفرداتم في اللغة العربية.

ب)شرح المعلم الدرس بالسريعة حتى يصعب الطلاب في استيعاب المعنى من ذلك الكية

الشرح دقيقا، ولاسيما للمبتدئين في تعلم اللغة العربية.

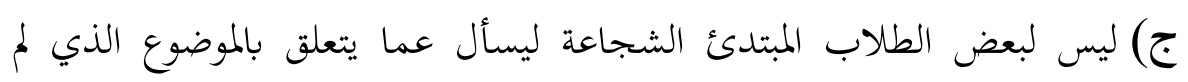

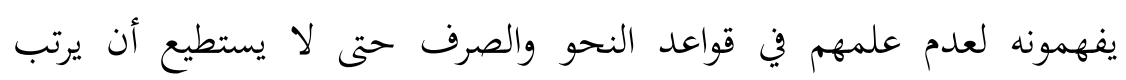

الجمل.

د) وعلى العكس، هناك بعض الطلاب الذين يخافون في إعطاء الأسئلة أو تقديم

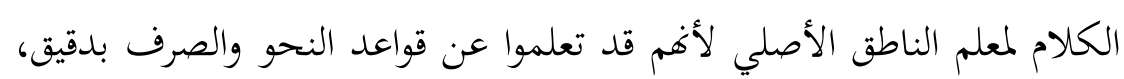

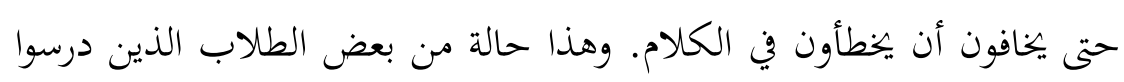
في المعهد السلافية من قبل.

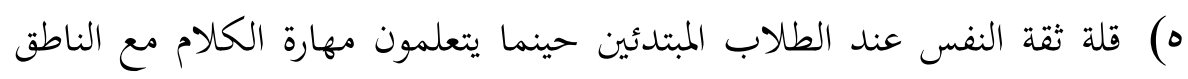
الأصلي، إلا الطلاب المجتهدون فيه.

4. المناقشة حول المزايا والنقائص من تدريس مهارة الكلام مع الناطق الأصلي

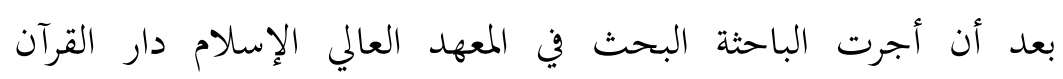

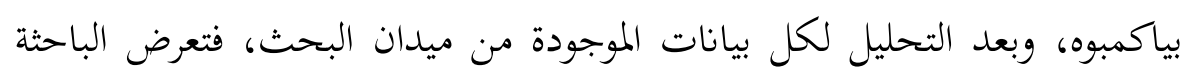

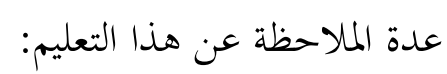

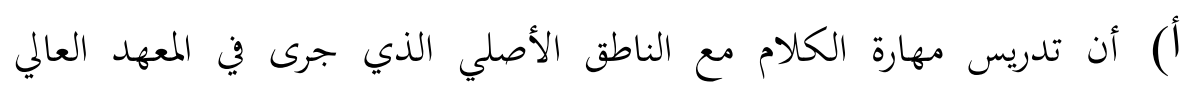

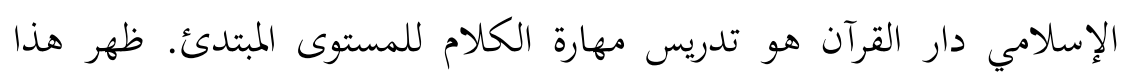

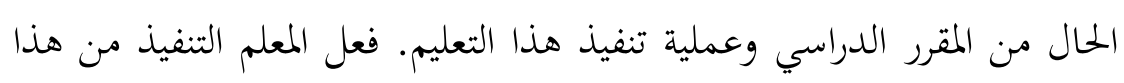
التعليم في شكل محادثة أو الحوار نموذجيا، وهناك حفظ بعض المغ الحوارات والأسئلة 
الإستيعابية التي يجيبها الطلاب شفهيا، وهذه العملية مناسبة بما شرحه رشدي

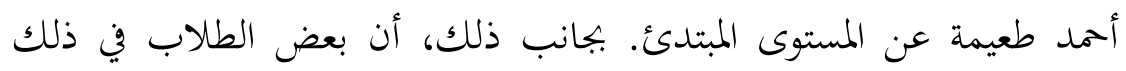

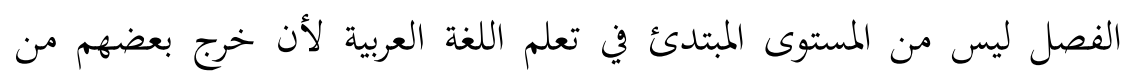

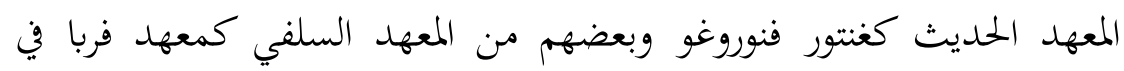

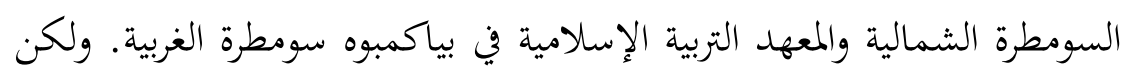
خرج الآخرون من المدرسة المتوسطة الإسلامية والمدرسة المتوسطة العامة، وليس لهم خبرة كثيرة في تعليم اللغة العربية من قبل.

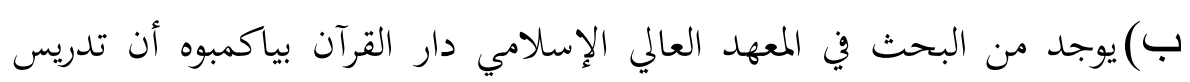

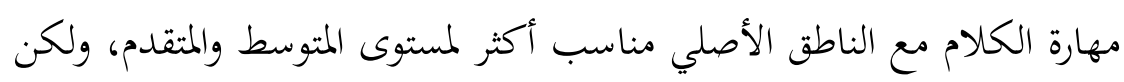

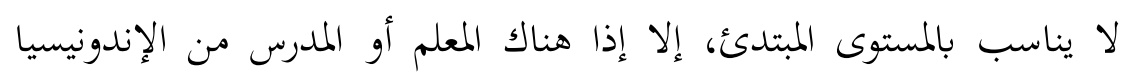

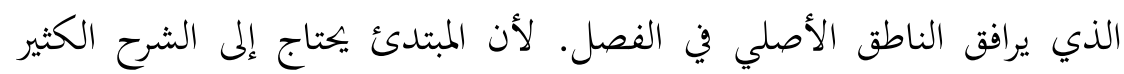

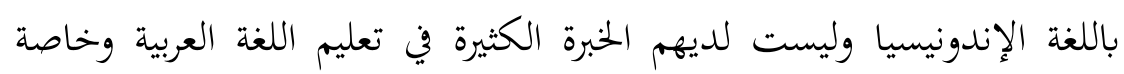

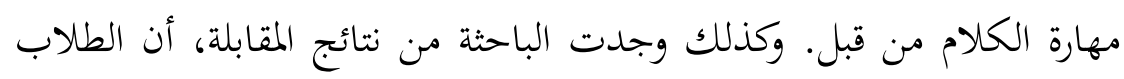

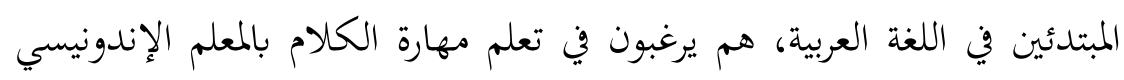

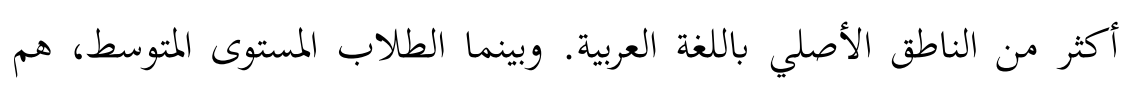

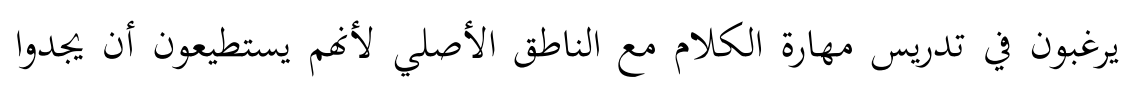
خبرة كثيرة وعلوم الكثيرة لتطوير مهارقم في الكلام بالمثال الصحيح.

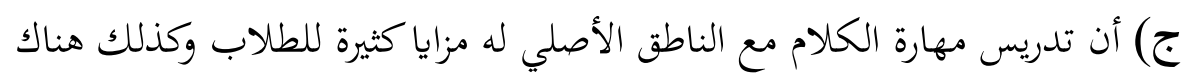

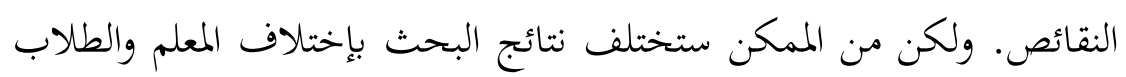

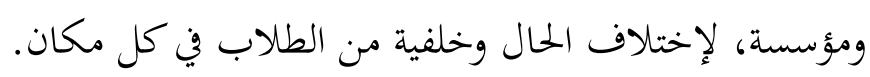




\section{JLIC}

الخاتمة

أن تنفيد عملية تعليم وتعلم مهارة الكلام مع النطق الأصلي في المعهد العالي الإسلامي دار القرآن بياكمبوه هو تدريس مهارة الكلام للمستوى المبتدئ. هناك المزايا

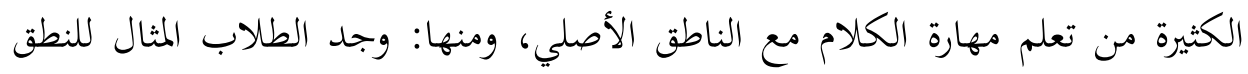

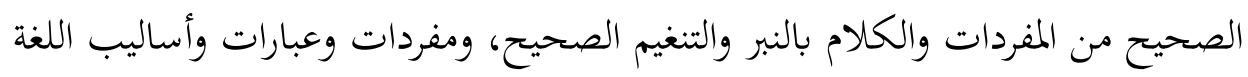

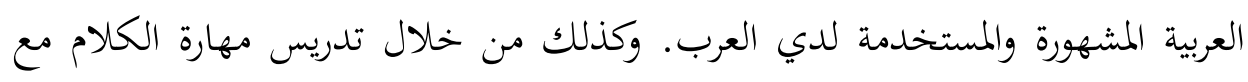
الناطق الأصلي وجد الطلاب المثير والحماسة والتشجيع لترقية قدرقم في مهارة الكلام.

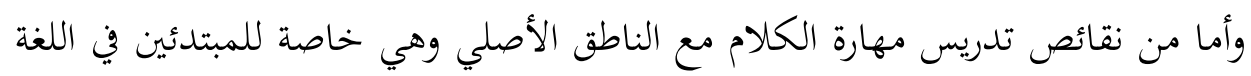
العربية، هم يصعبون في فهم الشرح من المعلم لسرعته في التكلم ولقلة مفرداقم العربية

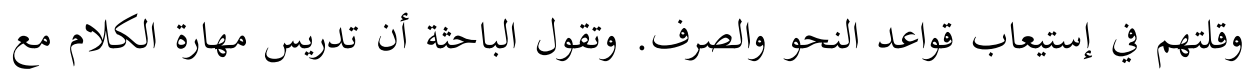
الناطق الأصلي، مناسب أكثر للمستوى المتوسط والمتقدم. 
جاسم الجبوري وهاشم السلطاني، المناهج وطرائق تدريس اللغة العربية. عمان: مؤسسة دار الصادق الثقافية. 2013

رشدي أحمد طعيمة. تعليم العبية لغير الناطقين بها مناهجه واساليبه. الرباط: منشورات المنظمة الإسلامية للتربية والعلوم والثقافة-ايسيسكو -. 1989

رشدي أمد طعيمة وعلي أحمد مدكور وإيمان أمد هريدي. المرجع في مناهج تعليم اللغة العبية للناطقين بلغات أخرى. القاهرة: دار الفكري العربي. 2010

صايش كهينة ويوسف خوجة سعيدة. المحادثة ودورها في تنمية مهارة التحدّث في مرحلة التعليم الابتدائي السنة الخامسة- أنموذجا- .جامعة عبد الرمن ميرة. 2016

صلاح عبد المجيد العربي. تعلّم اللغات الحيّة وتعليمها بين النظريّة والنطبيق. بيروت: مكتبة لبنان. 1981

على أممد مدكور. تدريس فنون اللغة العربية. القاهرة: دار الفكر العربي. 2002

فتحي علي يونس ومحمد عبد الرؤوف الشيخ. المرجع في تعليم اللغة العربية للأجانب من النظرية إلى التطبيق. القاهرة: مكتبة وهبة. 2003

Vol.5, No. 1, ، Aمد إيفان ألفيان. مهارة الكلام وتعليمها. البلة العلمية "Arabia" Januari-Juni 2013 


\section{ILIC \\ Journal of Language Intelegence and Culture}

محمد صالح الشنطي. المهارات اللغوية. المملكة العربية السعودية: دار الأندلس للنشر

والتوزيع. 1995 